\title{
Baseline survey for the implementation of insecticide treated mosquito nets in Malaria control in Ethiopia
}

\author{
Daddi Jima ${ }^{1}$, Gezahegn Tesfaye ${ }^{1}$, Wakgari Deressa ${ }^{2}$, Adugna Woyessa ${ }^{1}$, Daniel Kebede ${ }^{1}$, Desta Alamirew ${ }^{1}$
}

\begin{abstract}
Background: Insecticide treated mosquito nets (ITNs) have raised a renewed interest to serve as tools for malaria control in Africa. The use of this control method has been proved to be a cost-effective means for the control of malaria. However, little is known the acceptability and utilization of mosquito nets in Ethiopia.

Objectives: The objective of this study is to provide relevant information about the knowledge, attitude and experience of communities about malaria and its preventive methods, particularly the acceptability and affordability of ITNs.

Methods: A descriptive cross-sectional study was carried out in five different parts of Ethiopia in January and February 1999. A multi-stage sampling method was used to select 1,933 households for the study. Data were collected by interviewing household heads or their representatives.

Results: Ninety-five percent of the participants perceived fever, headache and chilling of the body as the main symptoms of malaria. More than $87 \%$ of the interviewees correctly identified the names of the anti-malarial drugs, chloroquine and SP. About $93 \%$ of the participants knew that malaria could be transmitted through mosquito bites. Mosquitoes are known to breed on stagnant water (83\%). More than $43 \%$ of the respondents replied that DDT, in combination with other control measures, could prevent malaria. Forty-one percent of the respondents had heard about the mosquito net. Only 5.3\% of the respondents in the survey reported the presence of at least one mosquito net in their households. Most of the respondents (92.5\%) were interested in using mosquito nets sometime in the future. The most preferred mode of obtaining ITNs was on loan basis (60\%). Accordingly, $24 \%, 20 \%$ and $16 \%$ were willing to pay in three, six, and nine months of installments and above, respectively. Forty-percent of the study participants were ready to buy it in cash. Of the 1,696 respondents, 47\% suggested 10 Birr or less, $11 \%$ between 11 and 20 Birr, 28\% from 2150 Birr and the rest (14\%) mentioned 51 Birr and above as the appropriate price for purchasing a single ITN.

Conclusion: The utilization of mosquito nets at the time of the study was very low. However, acceptability and willingness to use ITNs for malaria prevention was very high. Thus, the expanding ITN implementation and increasing its coverage for malaria control both in urban and rural malarious areas of the country is crucial. It is recommended that communities should be strongly sensitized on the importance of ITNs for malaria control and the availability and affordability should be insured. [Ethiop.J.Health Dev. 2005;19(1):16-23]
\end{abstract}

\section{Introduction}

Malaria remains a major public health problem particularly in many tropical countries, resulting in decreased productive capacity and increased poverty despite the intensive attempts being, exerted to control it especially in sub-Saharan Africa $(1,2)$.

Ethiopia is one of the other sub-Saharan African countries that are seriously affected by the disease. Three-fourths of the total area of the country is malarious with more than two-thirds of the total population being at risk of malaria infection $(3,4)$. Altitude and climatic factors are the main determinants for malaria epidemiology in the country and areas below 2000 meters above are classified as malarious $(4,5)$. However, a recent report has shown that malaria occurs in highland fringe areas including in urban sites; the main factor being climate change (6). The disease is mostly seasonal in nature and unstable in characteristic, thus, predisposing a majority of the population to frequent epidemics.

Of all the four Plasmodium species in the country, the two epidemiologically important species are Plasmodium falciparum and $P$. vivax, type $60 \%$ and $40 \%$, of the cases respectively. Anopheles arabiensis is the principal vector that can adapt to different ecological locations in Ethiopia (4). This species type predominantly exists in small sunlit breeding sites flourishing after cessation of the rainy season and is known to play a crucial role in epidemic situations. Obviously, this is one of the major challenges in vector control.

Early detection and prompt treatment of malaria cases, selective vector control (indoor residual spray, use of insecticide treated mosquito nets and source reduction) and epidemic prevention and control are the major strategies adopted in the country. So far, the application

${ }^{1}$ Malaria and Other Vector-borne Diseases Prevention and Control Team, Federal Ministry of Health, Addis Ababa, P.O. Box 1234,Phone150993, E-mail: malaria@telecom.net.et, Ethiopia; ${ }^{2}$ Department of Community Health, Faculty of Medicine, Addis Ababa University, Addis Ababa, Ethiopia 
of in-house insecticide spraying has been at the center of vector control operations (7).

Currently, insecticide treated mosquito nets (ITNs) have received serious attention and have raised renewed interest to serve as tools in malaria control. In Africa, the use of this control strategy has been proved to be costeffective means for the control of malaria, especially among children under 5 years of age and pregnant women.

Studies conducted in different African countries have shown the effectiveness of ITNs $(8,9,10)$. Moreover, other controlled trials have also confirmed an over-all reduction in child mortality $(11,12,13)$.

Thus, based on these epidemiological evidences, it could be agued that ITNs have become one of the major components of vector-targeted interventions in Africa (14). The first initiative to adopt this strategy in Ethiopia was made in 1997/8 with the support of WHO, and efforts have been made to scale-up this experience in some other malarious areas of the country. However, baseline information is not available at the national level to streamline the use of ITNs and promote their distribution at the community level at the moment. Since this strategy is a new initiative in the country, understanding the perception and willingness of the community towards using ITNs as well as the factors influencing its usage and distribution were the preliminary information required at the national level.

Ethiopia has adopted the use of ITNs as one of its vector control strategies primarily in selected malarious areas with the view to a gradual scaling-up of the intervention. The use of mosquito nets is, however, limited and there are a number of possible explanations for this low coverage. These may be due to lack of cultural exposure to the use of mosquito nets, lack of awareness, absence of a sustainable mechanism for the distribution of ITNS, low acceptance by the community, and concerns regarding its high cost. Since this strategy, as one of the vector control options in the country, is a new initiative, understanding the perceptions and willingness of the community towards using ITNs as well as the factors influencing its usage is a prerequisite for designing strategies aimed at scaling-up mosquito net implementation programmes in Ethiopia.

The rationale for selecting these areas was to initiate the introduction and implementation of ITNs in semi-urban and development project areas and gradually expand it to other malarious areas. The assumption was that the people residing in these areas might have awareness about mosquito nets and their importance in preventing malaria morbidity and mortality. These areas are mostly exempted from regular indoor residual spray activities.
The aim of this paper is, therefore, to provide information about the knowledge, attitude and experience of the community about malaria as a disease and its preventive methods, particularly acceptability, affordability and compliance to the use of mosquito nets, and factors influencing its possession and use in the study areas. This information is helpful for the further implementation and scaling-up of ITNs in the country.

\section{Methods}

Study sites: The study was conducted in Kebeles (lower administrative government structures) selected from the Southern Nations Nationalities and Peoples Regional (SNNPR), Oromia and Amhara Regional States. The study kebeles included Kebele 03 from Alaba zone of SNNP region, Gutin and Wonji from East Wollega and East Shewa zones of Oromia regional state, respectively. From the Amhara region, Kebleles 07 and 17 of Bahir Dar Zuria Wereda, and Metema 02, Genda Woha and Kumer Kebeles from Metema Wereda in North Gondar were included. Except for Wonji Sugar Factory study site in East Shewa, all the other study areas are located urban and semi-urban centers. These sites have an annual malaria transmission of three months or more and are presumed to represent the diverse eco-epidemiological conditions of malaria in the country.

Study design and sampling techniques: A descriptive cross-sectional study design and a multi-stage sampling procedure was employed for the study. The study areas were purposively selected to represent the rains malarious areas of the country in its socio-cultural, demographic and geographical diversity. Kebeles were then randomly selected from the list of kebeles, followed by a selection of households. The study unit was a household, and the sampling frame was the list of households found in each kebele.

The sample size was calculated using the formula for estimating a single proportion, which gave 1,933 households. The sample size was distributed to the selected kebeles in proportion the number of estimated households and the population of each kebele. The participating households were finally chosen by a systematic sampling method from the list of households found in each kebele. The data collection tool was first prepared in English and was then translated into Amharic for data collection. These questionnaires were then pretested before being administered.

Data collection, management and analysis: Data were collected from January to February 1999 using a pretested interviewer administered structured questionnaire specifically developed for this purpose. The questionnaires were then filled by the participating household heads or their representatives (if the household head was not available). The major variables included in the questionnaire were demographic factors, KAPs, 
possession of mosquito nets, utilization of ITNs and affordability, willingness to pay as well as a preferred mechanism of mosquito net distribution. The survey also elicited information on factors likely to influence the purchase and willingness of the community to pay for ITNs. In addition, information was collected about the presence of malaria cases in the household during the two weeks period prior to the interview.

Data collectors were recruited from the respective study areas and were trained to administer the questionnaires. They were particularly trained on ways of administering the questionnaire and conducting the interview through house-to-house visits. Completed questionnaires were checked for consistency and completeness by the supervisor. Data entry was accomplished using EPI INFO version 6.04. Data analysis was done using SPSS version 10.0 software.

Ethical Considerations: Approval to conduct the study was granted by the Federal Ministry of Health. Local administrative bodies and Wereda Health Offices were informed and involved in the study. Verbal consent was obtained from the study participants before administering the questionnaire. In addition, data collectors were made to give education on the prevention and control of malaria to the study participants at the end of each interview session.

\section{Results}

The total number of the study participants was 1,933; of these $62 \%$ were females. Of the total number of respondents, 38\% were from SNNPR, $43 \%$ were from Amhara and the rest 19\% were from Oromia region. Their socio-demographic characteristics are presented in Table 1 . Most of the respondents were young adults (31.9\%), Orthodox in religion (68.1\%), married (70.6\%), literate $(58.1 \%)$, house wives $(32.9 \%)$ and earned less than 100 Birr per month (55.3\%). Nearly 56\% and 6\% had access to radio and television, respectively.

The knowledge and beliefs of the participants about malaria transmission, mosquito breeding sites, malaria prevention methods is presented in Table 2. About 93\% of the respondents knew that malaria could be transmitted through mosquito bites, while the rest replied that eating maize stalk, breathing contaminated air, making contacts with malaria patients and bed bugs/fleas could cause malaria. Moreover, $83 \%$ of the respondents said that mosquitoes breed on stagnant water followed by dirty places (11.6\%). More than $43 \%$ replied that spraying DDT in combination with other measures was a helpful method to prevent malaria. Surprisingly, above $15 \%$ of the respondents said that using mosquito net in combination with other vector control measures could be applied to prevent the occurrence of malaria.
Table 1: Socio-demographic characteristics of the study population, Ethiopia, 1999.

\begin{tabular}{|c|c|c|}
\hline Variable $(n=1933)$ & Number & Percent \\
\hline \multicolumn{3}{|l|}{ Age in years } \\
\hline $15-24$ & 417 & 21.6 \\
\hline $25-34$ & 616 & 31.9 \\
\hline $35-44$ & 498 & 25.8 \\
\hline $45-54$ & 253 & 13.1 \\
\hline$\geq 55$ & 149 & 7.7 \\
\hline \multicolumn{3}{|l|}{ Sex } \\
\hline Male & 730 & 38.0 \\
\hline Female & 1203 & 62.0 \\
\hline \multicolumn{3}{|l|}{ Ethnicity } \\
\hline Amhara & 838 & 43.3 \\
\hline Kembata & 222 & 11.4 \\
\hline Oromo & 204 & 10.6 \\
\hline Alaba & 193 & 10.0 \\
\hline Guraghe & 166 & 8.6 \\
\hline Wolayta & 145 & 7.7 \\
\hline Others & 165 & 8.5 \\
\hline \multicolumn{3}{|l|}{ Religion } \\
\hline Orthodox & 1124 & 68.1 \\
\hline Muslim & 586 & 30.3 \\
\hline Protestant & 205 & 10.6 \\
\hline Catholic & 18 & 1.0 \\
\hline \multicolumn{3}{|l|}{ Marital status } \\
\hline Married & 1364 & 70.6 \\
\hline Single & 297 & 15.4 \\
\hline Widowed & 137 & 7.1 \\
\hline Divorced & 135 & 7.0 \\
\hline \multicolumn{3}{|l|}{ Education Level } \\
\hline Illiterate & 809 & 41.9 \\
\hline Can read and write & 155 & 8.0 \\
\hline Grades 1-6 & 431 & 22.3 \\
\hline Grades 7-12 & 420 & 21.7 \\
\hline Above 12 grade & 118 & 6.1 \\
\hline \multicolumn{3}{|l|}{ Occupational status } \\
\hline Housewife & 636 & 32.9 \\
\hline Merchant & 374 & 19.3 \\
\hline Farmer & 197 & 10.2 \\
\hline Daily laborer & 179 & 9.3 \\
\hline Government employee & 141 & 7.7 \\
\hline Factory worker & 133 & 6.9 \\
\hline Seeking a job & 100 & 5.2 \\
\hline Student & 96 & 5.0 \\
\hline Others & 77 & 4.0 \\
\hline \multicolumn{3}{|l|}{ Monthly income (in Birr)* } \\
\hline$\leq 100$ & 1068 & 55.3 \\
\hline $101-500$ & 710 & 36.7 \\
\hline$>500$ & 155 & 8.0 \\
\hline
\end{tabular}

Community involvement in the prevention and control of malaria was found to be high (Table 3). Most of the study population, more than $90 \%$ (1744), took part in malaria prevention and control measures. Participation was achieved through discussion and consultation with health workers (22.0\%), cleaning their surroundings (18.8\%), seeking early treatment $(7.9 \%)$, filling and draining of ditches (5.1\%), collaboration during DDT spraying 
activities (2.9\%) and the others involved in multiple prevention and control measures (33.5\%). The rest (9.8\%) were not directly involved in prevention and control interventions.

Table 2: Knowledge on malaria transmission, mosquito breeding sites and prevention methods, Ethiopia, 1999.

\begin{tabular}{lll}
\hline Variable & Number & Percent \\
\hline $\begin{array}{l}\text { Mode of malaria transmission } \\
\text { (n=1933) }\end{array}$ & & \\
$\quad$ Mosquito bite & 1790 & 92.6 \\
$\quad$ Breathing bad air & 19 & 1.0 \\
$\quad$ Contact with a malaria patient & 19 & 1.0 \\
$\quad$ Exposure to rain & 18 & 0.9 \\
$\quad$ Bad smell & 18 & 0.9 \\
$\quad$ Eating maize stalk & 13 & 0.7 \\
$\quad$ Wind/cold air & 8 & 0.4 \\
$\quad$ Bedbug/flea & 4 & 0.2 \\
$\quad$ Others & 44 & 2.3 \\
Mosquito breeding sites & & \\
(n=1790) & & \\
Stagnant water & 1489 & 83.0 \\
$\quad$ Dirty areas & 206 & 11.6 \\
$\quad$ Didn't know & 61 & 3.4 \\
$\quad$ Others & 34 & 2.0 \\
Prevention methods (n=1933) & & \\
$\quad$ Cleaning the surroundings & 157 & 8.1 \\
$\quad$ Draining and filling ditches & 108 & 5.6 \\
$\quad$ DDT spraying & 92 & 4.8 \\
$\quad$ Chemotherapy & 92 & 4.8 \\
Fumigation and fire smoking & 34 & 1.8 \\
$\quad$ Mosquito net & 24 & 1.2 \\
DDT and one or more & 837 & 43.3 \\
of the above measures & & \\
Mosquito net and one or & 297 & 15.4 \\
more of the above measures & & \\
Didn't know & 292 & 15.1 \\
\hline
\end{tabular}

Table 3: Community involvement in malaria prevention and control measures, Ethiopia, 1999.

\begin{tabular}{lll}
\hline Variable (n=1933) & Number & Percent \\
\hline Discuss/consult health worker & 426 & 22.0 \\
Clean surroundings & 363 & 18.8 \\
Seeking early treatment & 152 & 7.9 \\
Filling and draining & 98 & 5.1 \\
Collaborate during DDT spray & 57 & 2.9 \\
Multiple measures & 648 & 33.5 \\
Not involved & 189 & 9.8 \\
\hline
\end{tabular}

On the other hand, $95 \%$ of the study participants perceived fever, headache and chills as the main signs and symptoms of malaria (Table 4). More than $87 \%$ of the interviewees, also correctly identified the names of the currently used anti-malarial drugs, name chloroquine and SP. With regard to malaria, morbidity and preference of health facilities, $98 \%$ of the 1,886 respondents had their first visit to health care facilities including public and private health services as well as malaria control laboratories, drug venders/pharmacy and CHWs seeking treatment for malaria. A few of the respondents also reported the use of herbalists and other healthy care providers. Out of the total households involved in this study, $81 \%$ had at least one family member who had experienced one malaria attack during the two weeks prior to the survey. About $48 \%$ of the households had two to five family members who were sick due to malaria and $27.5 \%$ had only one family member who was sick of the disease.

Table 4: Knowledge about the symptoms of malaria, antimalarial drugs and preference of health service visit for malaria illness, Ethiopia, 1999.

\begin{tabular}{lll}
\hline Variable & Number & Percent \\
\hline $\begin{array}{l}\text { Signs and symptoms of malaria } \\
\text { (n=1933) }\end{array}$ & & \\
$\quad \begin{array}{l}\text { Fever, headache, chills } \\
\text { Joint \& muscle pain, }\end{array}$ & 1836 & 95.0 \\
$\quad$ nausea/vomit & 26 & 1.3 \\
$\quad$ Others & 71 & 3.7 \\
$\begin{array}{l}\text { Antimalarial drugs (n=1933) } \\
\quad \text { Chloroquine }\end{array}$ & 567 & 29.0 \\
$\quad$ SP & 193 & 10.0 \\
$\quad$ Chloroquine and SP & 925 & 48.0 \\
$\quad$ Other & 34 & 2.0 \\
$\quad$ Didn't know & 214 & 11.0 \\
& & \\
$\begin{array}{l}\text { First visit when sick of malaria } \\
\text { (n=1933) }\end{array}$ & & \\
$\quad$ Gov't health care facility & 1270 & 67.3 \\
$\quad$ Malaria control laboratory & 399 & 21.2 \\
$\quad \begin{array}{l}\text { Private clinics } \\
\text { Drug vendor/pharmacy }\end{array}$ & 163 & 8.6 \\
$\quad$ CHWs & 18 & 1.0 \\
$\quad$ Herbalist & 2 & 0.1 \\
$\quad$ Others & 1 & 0.1 \\
$\quad$ No response & 33 & 1.7 \\
Number of family members sick \\
of malaria in the two weeks \\
period (n=1933)
\end{tabular}

The knowledge and practice about the mosquito net and its utilization is indicated in Table 5. Forty-one percent of the respondents had heard about the mosquito net. It appears that a majority of the study participants did not know about mosquito nets at all. Among those respondents who had heard about mosquito nets, $47.4 \%$ obtained the information from health personnel, 35.1\% from the mass media (mainly radio and television), $3 \%$ from leaflets and brochures and out of those who have ever heard about the mosquito net (793) about 13\% have owned it. However of the total 1,933 households, only 102 (5.3\%) respondents in the survey reported the presence of at least one mosquito net in their households at the time of the survey, and 1,831 (94.7\%) said had no mosquito nets at all (Table 6). With regard to the use of ITNs in the households who possessed one, 77 (75\%) 
reported that they used mosquito nets every day and throughout the night. However, $16.7 \%$ of the households used it consistently only during part of the night. On the contrary, about $7.8 \%$ of them said their used it sometimes or during the daytime.

\section{Table 5: Community knowledge and practices about} the mosquito net, Ethiopia, 1999

\begin{tabular}{lll}
\hline Variable & Number & percent \\
\hline Ever heard about the mosquito & & \\
net (n=1933) & & \\
$\quad$ Yes & 793 & 41.0 \\
$\quad$ No & 1140 & 59.0 \\
$\begin{array}{l}\text { Sources of information (n=793) } \\
\quad \text { Health personnel }\end{array}$ & 376 & 47.4 \\
$\quad$ Mass media & 278 & 35.1 \\
$\quad$ Leaflets, brochure & 22 & 2.8 \\
$\quad$ Friends and colleagues & 8 & 1.0 \\
$\quad$ Neighbors & 6 & 0.7 \\
$\quad$ Two or more sources above & 6 & 0.7 \\
$\quad$ Others & 97 & 12.2 \\
$\quad$ & & \\
Households owning mosquito & & \\
net (n=793) & 102 & 12.9 \\
$\quad$ Yes & 691 & 87.1 \\
$\quad$ No & & \\
Time of using mosquito net & & \\
(n=102) & & 75.0 \\
$\quad$ Every day throughout the night & 77 & 16.7 \\
$\quad$ Every day only part of the night & 17 & 4.9 \\
$\quad$ Some times & 5 & 2.9 \\
$\quad$ During day time & 3 & \\
$\quad \begin{array}{l}\text { Reasons for not owning a } \\
\text { mosquito net (n=691) }\end{array}$ & & \\
$\quad$ Lack of awareness & & \\
$\quad$ Unavailability of mosquito & 417 & 60.3 \\
$\quad \begin{array}{l}\text { Unaffordable to buy } \\
\text { Others }\end{array}$ & 83 & 25.5 \\
\hline
\end{tabular}

A large majority of the households did not own any mosquito net, the main reasons cited being lack of knowledge (60.3\%), unavailability of mosquito nets (25.5\%) and lack of money to purchase it (12.0\%) (Table
5). Surprisingly, more than half (52\%) of the respondents perceived the importance of using mosquito net to prevent morbidity and mortality from malaria. On the contrary, $19.6 \%$ replied that mosquito net had no impact on malaria morbidity and mortality, and the rest (28.4\%) gave "don't know" responses. The distribution of households with and without mosquito nets is shown in Table 6. Of the total households that have mosquito nets, 10 (1.2\%) were located in Alaba Kebele 03, 6 (2.4\%) in Gutin, $2(0.8 \%)$ in Wonji, 14 (4.8\%) in Bahir Dar and $70(23.2 \%)$ in Metema study areas. Wide variations were observed in the possession of mosquito nets across the different study areas.

Interest to use, affordability and preferred route of distribution of mosquito net are presented in Table 7. Almost all the respondents (92.5\%) were interested in the future use of mosquito nets if available, mostly because they felt that it would provide them with better protection from malaria. Most of the respondents preferred to have nets on loan basis $60 \%$ of them preferring to pay the within three months to one year period of time. The rest $40 \%$ said they were ready to pay in cash immediately.

Affordability is one of the determinant factors that impedes the possession and use of ITNs. This becomes more severe in areas where the community lacks prior knowledge and culture of using the nets. They were also asked about how much money they would be willing to pay for purchasing a single mosquito net. Of the 1696 respondents, $47 \%$ suggested 10 Birr or less, $11 \%$ said between 11 and 20 Birr, 28\% from 21-50 Birr and the rest (14\%) mentioned 51 Birr and above (Table 7). The majority did not want to spend more than 50 Birr for purchasing a mosquito net. Another important question was on ways of distributing ITNs to the community who needed it. Sixty-nine percent of the study group preferred health facilities to distribute the nets, while $27 \%$ preferred the distribution of ITNs through Kebele administrative offices. The rest either preferred other routes of distribution or gave “don’t know” responses.

Table 6: Distribution of mosquito net ownership by households according to the specific study areas, Ethiopia, 1999.

\begin{tabular}{lllllll}
\hline Region & Zone & Wereda & $\begin{array}{c}\text { Study } \\
\text { area }\end{array}$ & $\begin{array}{l}\text { Non-owners of } \\
\text { mosquito } \\
\text { net (\%) }\end{array}$ & $\begin{array}{l}\text { Owners of } \\
\text { mosquito } \\
\text { net (\%) }\end{array}$ & $\begin{array}{l}\text { Total } \\
\text { households } \\
\text { (\%) }\end{array}$ \\
\hline SNNP & Kembata/Alaba & Alaba & Alaba 03 & $830(98.2)$ & $10(1.2)$ & $840(43.4)$ \\
Oromia & East Wellega & Gida Kiremu & Gutin & $245(97.6)$ & $6(2.4)$ & $251(12.9)$ \\
& East Shewa & Adama & Wonji & $249(99.2)$ & $2(0.8)$ & $251(12.9)$ \\
Amhara & Bahir Dar & Bahir Dar Zuria & Bahir Dar & $275(95.2)$ & $14(4.8)$ & $289(14.9)$ \\
& North Gondar & Metema & Metema & $232(76.8)$ & $70(23.2)$ & $302(15.6)$ \\
\hline Total & 5 & 5 & 5 & $1831(94.7)$ & $102(5.3)$ & $1933(100)$ \\
\hline
\end{tabular}




\begin{tabular}{|c|c|c|}
\hline Variable $(n=1933)$ & Number & Percent \\
\hline \multicolumn{3}{|c|}{ Need to use ITNs if available $(n=1933)$} \\
\hline Yes & 1788 & 92.5 \\
\hline No & 121 & 6.3 \\
\hline Don't know & 24 & 1.2 \\
\hline \multicolumn{3}{|c|}{ Need loans to use ITNs $(n=1933)$} \\
\hline Yes & 1696 & 87.7 \\
\hline No & 237 & 12.3 \\
\hline \multicolumn{3}{|c|}{ Duration of loan payment $(n=1696)$} \\
\hline Immediately/ in cash & 686 & 40.0 \\
\hline Three months & 413 & 24.0 \\
\hline Six months & 330 & 20.0 \\
\hline Nine months & 30 & 2.0 \\
\hline One year & 221 & 13.0 \\
\hline Others & 16 & 1.0 \\
\hline \multicolumn{3}{|c|}{ Suggested price for a single ITN $(n=1696)$} \\
\hline$\leq 10$ Birr & 792 & 47.0 \\
\hline 11-20 Birr & 181 & 11.0 \\
\hline 21-50 Birr & 484 & 28.0 \\
\hline$>50$ Birr & 239 & 14.0 \\
\hline \multicolumn{3}{|c|}{ Suggested mechanism for ITN distribution $(n=1696)$} \\
\hline Health facility & 1168 & 69 \\
\hline Kebele administration & 455 & 27 \\
\hline Don't know & 34 & 2.0 \\
\hline Others & 39 & 2.0 \\
\hline
\end{tabular}

\section{Discussion}

The aim of this study was to assess the knowledge, perceptions and practices of the community about malaria, as well as its transmission and prevention methods. Furthermore, it aimed to determine the coverage of ITNs mainly in urban and semi-urban areas, and factors influencing its possession and usage. Although the association of malaria with mosquitoes is widespread in these communities, other causal factors of malaria such as traditional beliefs like eating maize stalks, contact with malaria patients, exposure to rains and cold weather, bad smell and dirty water were frequently suggested.

The awareness about the association between mosquito and malaria in the present study is much higher than the findings reported in previous studies $(15,16)$. The study participants included in this study were mainly from the urban areas unlike those of the previous studies who resided mainly in rural areas. In addition, different interventions particularly those made to raise the awareness of the community about malaria and its control in the urban areas could be a possible explanation for the high awareness of malaria. In this study the respondents indicated that stagnant water is the main mosquito breeding site. Previous studies have also confirmed similar findings $(15,17,18)$. The awareness on the relationship between mosquitoes and malaria transmission in the study community is highly important for the possession and utilization of mosquito nets. It is speculated that knowledge of this association predicts high mosquito net use.
Almost all of the participants in this study had knowledge about the main signs and symptoms suggestive of malaria as in all studies. Knowledge is usually high in areas with low to moderate transmission rates and where people are aware of the clinical manifestations of the disease (1518). However, it might be low in areas of holo-endemic transmission where the population has protective immunity against malaria (17).

The medications taken for the treatment of malaria episode were mainly antimalarial drugs. Unlike in the rural areas, malaria cases in our study area were usually first identified and treated in public health care facilities and malaria control laboratories. The utilization of private health facilities, traditional herbal remedies and community health workers was very low in the study areas. This is mainly due to the fact that the coverage and accessibility of public health facilities in the study area is relatively high compared to that in rural malarious areas. However, it has been demonstrated that the coverage of malaria control can be increased substantially by involving communities particularly by training community health workers and mother coordinators especially on correct antimalarial drug use for children $(19,20)$.

This study highlights several important issues for the implementation of ITNs as a malaria control strategy. The proportion of people who had not heard about ITNs was significant (59\%). Similarly, the proportion of households who owned ITNs among those who had 
heard about it was only 5.3\%. Among these, those who reported inappropriate use of ITNs were nearly $25 \%$. An extremely large gap exists between those who have heard about ITNs and those who owned it and between those who possessed and used mosquito nets appropriately. This discrepancy could be because of either the awareness of the community about ITNs is poor or may reflect the relative unavailability of mosquito nets, suggesting that, at the time of the survey, mosquito net use for malaria control was not being adequately promoted in many parts of the country.

This study also suggests ways of increasing demand in relation to the implementation of ITN programme. For example, a significant proportion (59\%) of households who are willing to buy would prefer making payments in installments. This may ensure greater coverage and make ITN affordable to those who may not be able to purchase it immediately and in cash.

The other important issue that should not be overlooked with regard to the affordability of ITNs is the time when the households would need ITN and the time when they would have most money available to buy them. Because of seasonality of crops and income generated, people residing in most parts of the country may prefer to purchase ITN after the harvest. If the perceived risk of malaria is low during these times, spending money on ITNs may not be perceived as a high priority (21). But when the need is perceived as highest, people may not have adequate money for buying mosquito nets. The time for the occurrence of peak malaria transmission associated with epidemics in Ethiopia is during the months of September to December. This appears to be inconsistent with the time when most people in the country have money, during January to March, after harvest. During this time people can easily sell their agricultural products and would be more willing to buy ITNs, but these are the months when the risk of malaria is to be low. Therefore, the decision makers engaged in promoting ITNs might be expected to consider the local disease burden as well as the appropriate period of the year convenient to the community for paying.

The affordability and possession of mosquito nets are not the only factors that affect ITN use and acceptance. The seasonality of malaria and mosquito abundance is also equally important. In surveys conducted in Ghana, net use was considerably higher in the rainy season than the dry season mainly due to the abundance of mosquitoes as nuisances and the perceived risk of malaria during the rainy season (21). This is particularly true for Ethiopia where the transmission of malaria and abundance of mosquito population vary across the seasons of the year. When the perceived malaria risk and mosquito density is high, mosquito nets are highly used. But when the mosquito density coupled with malaria risk is low, people may not see the need of continued mosquito net use.
Therefore, the seasonality of malaria and unavailability of mosquito nets for the needy people with an appropriate price can be the barriers against the high coverage of mosquito net particularly in poor rural communities. These community factors have to be taken into considerations during the implementation of ITN programmes.

This study was not conducted without a limitation. The study was carried out mainly in urban and peri-urban areas during January and February, the time when malaria problem in the country is low. This could lead the respondents to underestimate the risk for malaria and willingness to purchase mosquito nets. It could have been better to undertake such kind of studies during the peak transmission of malaria both in urban and rural areas to elucidate the heartfelt needs of the community. Nevertheless, this study provides useful information about malaria and ITNs that may be of practical importance.

In conclusion, the utilization of mosquito nets at the time of this survey was very low. However, acceptability and willingness of the community to use ITNs for malaria prevention was very high. It is expected that the expansion of ITN implementation and increasing its coverage both in the urban and rural malarious areas of the country may lead to the success of malaria control. To this end, it is recommended that communities should be strongly sensitized on the importance of treated mosquito nets for malaria prevention and the availability and affordability should be insured. As regular assessment and monitoring of net possession and use provide the best available means to track progress in coverage with this principal malaria intervention, districtlevel rapid assessments of household possession and usage of nets should be encouraged and supported for program evaluation.

\section{Acknowledgments}

We would like to acknowledge the WHO country office for Ethiopia and the Federal Ministry of Health for their financial and technical support of this study. We gratefully acknowledge Oromia, SNNP and Amhara regional health bureaus, for their contribution during the selection of study sites and data collection. We would also like to pass our sincere appreciation and gratitude to the study communities for their active participation in the study. Lastly, we are greatly indebted to Miss Misrak Tesfaye and Mrs Mery Kifle for their intolerable time during data entry.

\section{References}

1. World Health Organization. A global strategy for malaria control. Geneva, Switzerland, 1993.

2. World Health Organization. WHO expert committee on malaria: twentieth report. Technical Report Series (No. 892), 2000.

Ethiop.J.Health Dev. 2005;19(1) 
3. Ministry of Health. Malaria control profile. Disease Prevention and Control Department. Addis Ababa, 2000.

4. Tulu AN. Malaria. In: Kloos H and Zein ZA., (eds). The ecology of health and disease in Ethiopia. Boulder, Westview Press, 1993, Pp. 341-352.

5. Gebremariam, N. Malaria. In: Zein, Z.A., Kloos, H., (eds). The Ecology of Health and Disease in Ethiopia. Ministry of Health, Addis Ababa, 1988, Pp 136-150.

6. Woyessa, A. The elucidation of malaria transmission and its prevalence in highland urban area of Akaki Town. [MSc Thesis]. Addis Ababa University, 2001, 120Pp.

7. Ministry of Health. National Five-Year Strategic Plan for Malaria Control in Ethiopia: 2001- 2005. Malaria and Other Vector Borne Diseases Prevention and Control Team, Disease Prevention and Control Department, Ministry of Health, Addis Ababa, 2001.

8. Choi, H.W., Breman, J.G., Teutsch, S.M., Liu S, Hightower, A.W. and Sexton, J.D. The effectiveness of insecticide-impregnated bed nets in reducing cases of malaria infection: a meta-analysis of published results. Am J Trop Med Hyg 1995; 52(5): 377-382.

9. Binka F.N., Kubaje, A., Adjuik, M., Williams, M.K, Lengeler, C., Maude, G.H. et al. Impact of permethrin impregnated bednets on child mortality in Kassena- Nankana district, Ghana: a randomized controlled trial. Trop Med Int Health 1996; 1:147154.

10. Nevill, C.G, Some, E.S., Mung'ala V.O., Muteme, W., New, L., Marsh K. et al. Insecticide-treated bednets reduce mortality and severe morbidity among children on the Kenyan coast. Trop Med Int Health 1996, 1:139-146.

11. Alonso, P.L., Lindsay, S.W., Armstrong, S.J., Konteh, M., Keita K., Marshal, C. et al. A malaria control trial using insecticide-treated bed nets and targeted Chemoprophylaxis in a rural area of The Gambia, west Africa 5: design and implementation of the trial. Trans R Soc Trop Med Hyg 1993;87:3136.
12. Alonso, P.L., Lindsay, S.W., Armstrong, S.J., Konteh, M., Hill, A.G., David, P.H. et al. The effect of insecticide-treated bed nets on mortality of Gambian children. Lancet 1991; 337: 1499-1502.

13. D'Alenssadro, U., Olaleye, B.O., McGuire, W., Langerock, P., Bennet, S., Aikins, M.K. et al. Mortality and morbidity for malaria in Gambian children after introduction of an impregnated bed net program. Lancet 1995; 345: 479-483.

14. World Health Organization. The Abuja declaration and plan of action: an extract from the African summit on the Roll Back Malaria. WHO/CDS/ RBM/2000.17.Geneva. Switzerland, 2000.

15. Deressa, W., Ali, A., Enquosellassie F. Knowledge, attitude and practice about malaria, the mosquito and antimalarial drugs in a rural community. Ethiop J Health Dev 2003; 17(2): 99-104.

16. Yeneneh, H., Gyorkos, T.W., Joseph, L., Pickering, J. and Tedla, S. Antimalarial drug utilization by women in Ethiopia: a knowledge-attitudes-practice study. Bull World Health Org 1993; 71: 763-772.

17. Ongore, D., Kamunvi, F., Knight, R., and Minawa, A. A study of knowledge, attitudes and practices (KAP) of a rural community on malaria and the mosquito vector. East Afr Med J 1989; 66(2): 79-89.

18. Klein, R.E., Weller, S.C., Zeissig, R., Richards, F.O. and Ruebush, T.K. Knowledge, beliefs, and practices in relation to malaria transmission and vector control in Guatemala. Am J Trop Med Hyg 1995; 52(5): 383-388.

19. Gebreyesus, T.A., Witten, K.H., Getachew, A. et al. The community-based malaria control in Tigray, northern Ethiopia. A review of programme set-up, activities, outcomes and impact. Parasitologia 2000; 42: 255-240.

20. Kidane, G. and Morrow, R.H. Teaching mothers to provide home treatment of malaria in Tigray, Ethiopia: a randomized trial. Lancet 2000; 356(9229): 550-555.

21. Binka, F.N. and Adonso. P. Acceptability and use of insecticide impregnated bed nets in northern Ghana. Trop Med Int Health 1997; 2(5): 499-507. 

